\title{
Research on Heterogeneous Communication Network for Power Distribution Automation
}

\author{
Qiang YU ${ }^{1, a^{*}}$, Hui HUANG ${ }^{1, b}$, Yue YU ${ }^{1, c}$, Chuan LIU ${ }^{1, d}$ \\ ${ }^{1}$ State Grid Smart Grid Research Institute, Nanjing, China \\ ayuqiang@sgri.sgcc.com.cn, bhuanghui@sgri.sgcc.com.cn, cyuyue@sgri.sgcc.com.cn, \\ liuchuan@sgri.sgcc.com.cn
}

Keywords: Smart Grid, Power Distribution Automation, Heterogeneous Communication Network Abstract. To solve the problem of current communication network for smart distribution automation, key technologies of heterogeneous networks were analyzed and researched, including network resource management, dynamic network selection and intelligent switching strategy as well as channel protection algorithm in multiple access environments. A series of improvements and optimization methods were proposed.

\section{Introduction}

Smart grid distribution automation system consists of the distribution master site, sub-site, distribution terminals and communication networks [1], which structure shown in Fig. 1. Function of distribution master site including data processing, data storage and various applications deployments. The sub-site connects master site and terminals, upload data aggregation and regional monitoring \& control can be implemented. Distribution terminal is a measuring and control device which installed near power equipments, such as FTU for feeder automation controller, TTU for transformer monitoring and DTU for distribution switchgear operation. The communication network provides measuring data and control instructions transfer path for all device nodes above.

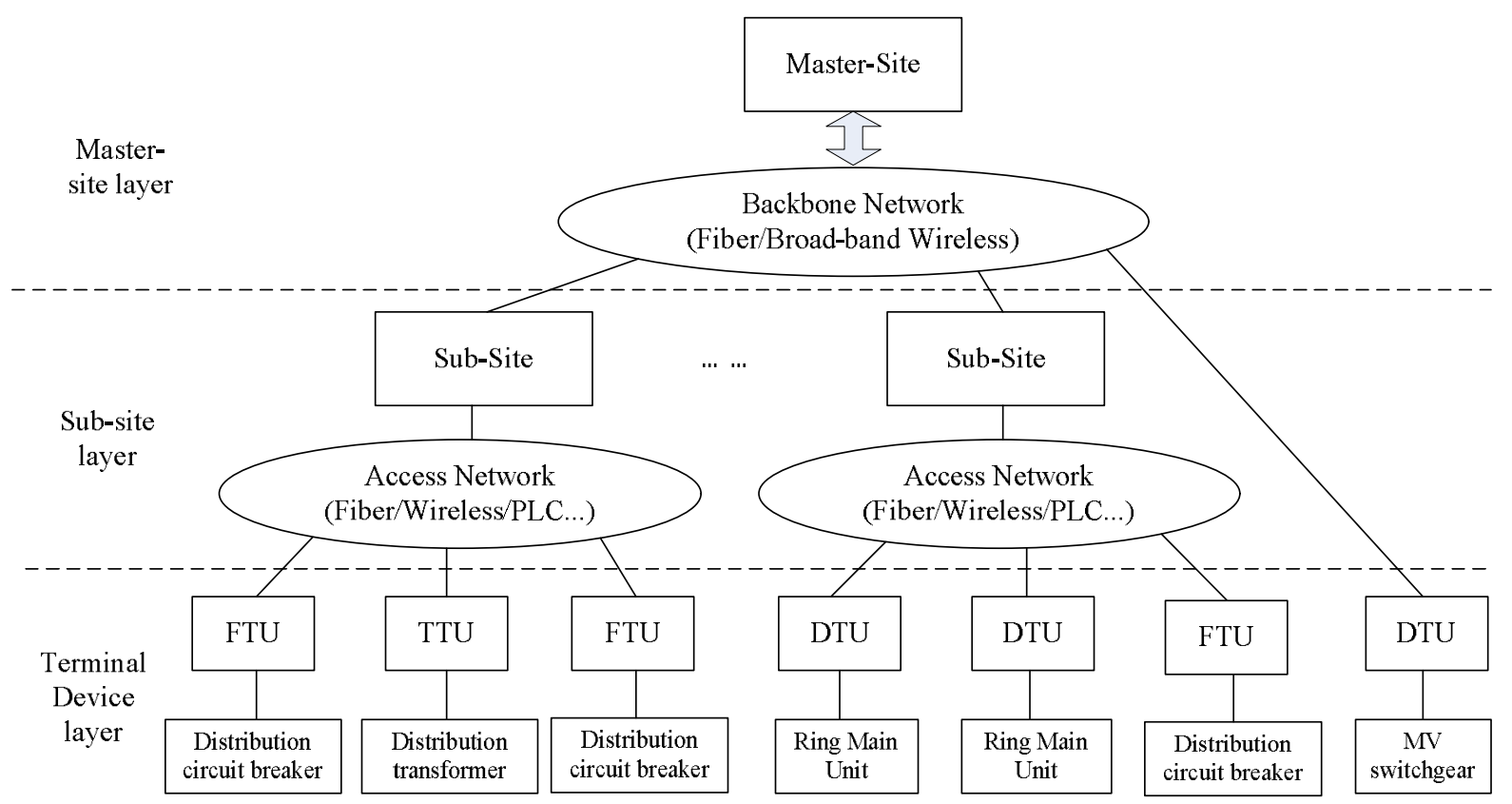

Fig 1. Distribution automation system architecture for Smart Grid

In order to meet the requirements such as network coverage of large, complex geographical environment, smaller communications capacity and different types of service data, the power communication access network in China was constructed with fiber-optic as base, wireless and PLC technology as supplemented[2][3]. Also, new technologies were also introduced and experimented to overcome flowing problems: 
a) The construction for the existing communications systems rely on electricity distribution application, the network may only carry single type of service data.

b) Communication networks were constructed redundantly, but resources from different systems cannot scheduling coordinately.

Thus causing a waste of bandwidth resources and construction investment. So, heterogeneous communication network technology was researched in this paper, main topics including network resource management, network selecting and switching in dynamic environment, smart routing algorithm as well as path protection were discussed.

\section{Network resource management}

With the development of the access network communication technology, communication resource allocation becomes richer. For example, in wireless communications, the resource of heterogeneous access network include the following aspects[4]:

1) Frequency, including channel bandwidth, sub-carrier modulation schemes and protection bands and etc.

2) Timing slot, including traffic slots, pilot symbols, protection time.

3) Space resource, including antenna polarization direction, the angle of the antenna, antenna number and etc.

4) Radio power, including signal power, interference power constraints, and the transmit power constraints.

Heterogeneous network resource management is a method with effective control mechanisms and policy set, to reach the target under conditions of limited transmission resources, and taking into account all QoS requirements of traffic data.

Compared with traditional network resource management, heterogeneous network resource management model includes not only centralized management, further comprising a distributed hierarchical management, the management between centralized and distributed. All management methods have their own advantages and disadvantages. As shown in Table 1. Three types of method are compared, concluded that hierarchical network resource management architecture is the future integration of heterogeneous network environments, which is most likely to adopted.

Table 1. Comparison of three modes of network resource management

\begin{tabular}{|c|c|c|c|}
\hline $\begin{array}{l}\text { Resource } \\
\text { management } \\
\text { mode } \\
\end{array}$ & Discription & Advantages & Disadvantages \\
\hline $\begin{array}{l}\text { Centralized } \\
\text { network } \\
\text { resource } \\
\text { management }\end{array}$ & $\begin{array}{l}\text { Suitable for tightly coupled } \\
\text { converged network architecture, } \\
\text { there is a centralized controller for } \\
\text { each access network management, } \\
\text { it can get resource usage across } \\
\text { multiple networks at the same } \\
\text { time and make unified allocation. }\end{array}$ & $\begin{array}{l}\text { Easy to maximize optimal use } \\
\text { of global resources and a reach } \\
\text { the target of full system } \\
\text { capacity. }\end{array}$ & $\begin{array}{l}\text { Less flexibility and } \\
\text { scalability, performance is } \\
\text { also a challenge for large } \\
\text { number of nodes. }\end{array}$ \\
\hline $\begin{array}{l}\text { Distributed } \\
\text { network } \\
\text { resource } \\
\text { management }\end{array}$ & $\begin{array}{l}\text { There is not a centralized } \\
\text { management entity to the } \\
\text { harmonization of the various } \\
\text { access mode, all sub-networks } \\
\text { have coordination function. }\end{array}$ & $\begin{array}{l}\text { Has good scalability and } \\
\text { flexibility features, ease of } \\
\text { management } \\
\text { maintenance, has lower } \\
\text { dependence on the center } \\
\text { decision-maker. }\end{array}$ & $\begin{array}{l}\text { Due to the lack of global } \\
\text { information support, it is } \\
\text { difficult to achieve the } \\
\text { optimal use of resources. } \\
\text { Additional exchange } \\
\text { signaling occupies lot of } \\
\text { bandwidth. }\end{array}$ \\
\hline $\begin{array}{l}\text { Hierarchical } \\
\text { network } \\
\text { resource } \\
\text { management }\end{array}$ & $\begin{array}{l}\text { The control function is distributed } \\
\text { to each network resource } \\
\text { management entity, combined } \\
\text { with the characteristics of } \\
\text { centralized and distributed } \\
\text { architectures. }\end{array}$ & $\begin{array}{l}\text { Set up on multiple resource } \\
\text { management entity, make } \\
\text { global optimization strategy to } \\
\text { get a good performance in } \\
\text { terms of network, system } \\
\text { overhead and network } \\
\text { flexibility. }\end{array}$ & $\begin{array}{l}\text { Requires prior research for } \\
\text { management structure and } \\
\text { design optimization. }\end{array}$ \\
\hline
\end{tabular}




\section{Network selecting and switching}

According to the main performer, network selection[5] can be divided into user-centric and provider-centric. The most effective network selection technique depends on many aspects of factors, such as the integration of heterogeneous network infrastructure, transmission environment, network load, service type, and so on.

Provider-centric mechanism uses a centralized control method to select the network access for each service, which can effectively balance the load between networks. However, this method involves proper scheduling problem between different network entities, increasing the cost of the system simultaneously. In addition, users can only obey central controller to make decisions, without flexiblily to choose the network.

User-centric network selection mechanism, depending on the user's algorithm of network selection, is a distributed network selecting method. It has a low implementation complexity and communication overhead, but lead to network load unbalanced and instability, this method is more suitable for an autonomous environment.

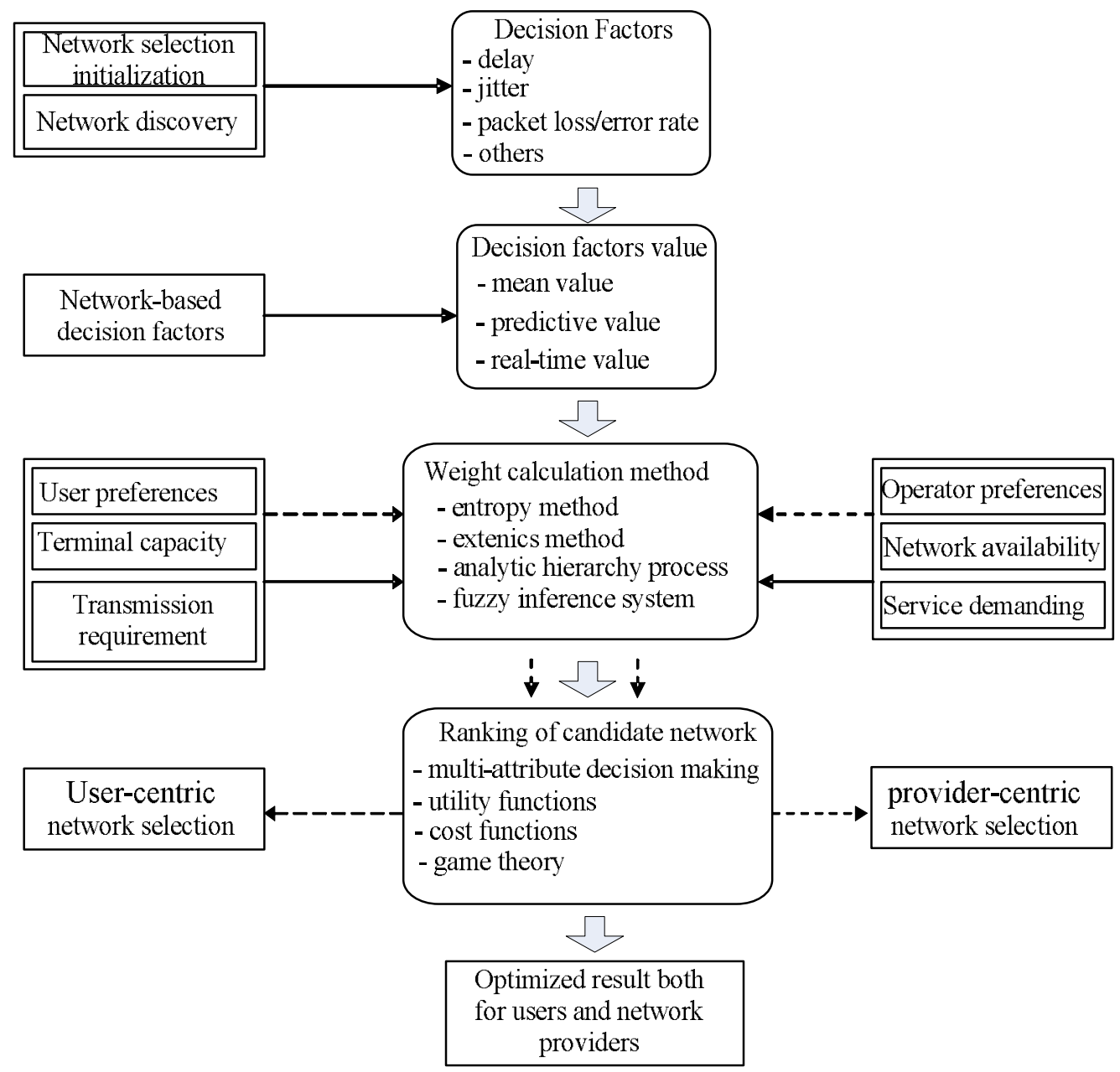

Fig 2 . The procedure of network switching

Network selection is a complex issue, usually it can be divided into four steps, As shown in Fig. 2, Sometimes, four steps are not necessary in the process, however, in most cases, each step represents a different period during the selection process and these are factors to be considered.

In a heterogeneous network, when the network status changes or there is adjustment of service traffic, the initial selection of network may not optimal, switching should be done by a certain mechanism. According to the type of network, it can be divided into horizontal and vertical switching. Horizontal switching means to switch between the networks with same access technology, while the vertical means to switch between network with different access technologies[6]. 
There are three processes when doing vertical switching: information gathering, switching decision and switching execution. In first process, details of network status and terminal equipment state information are gathered. Then, the optimal target network is determined by network selection algorithm during switching decisions progress. Finally, switching action is executed. Decision factors to be considered for vertical switching are shown in Fig. 3.

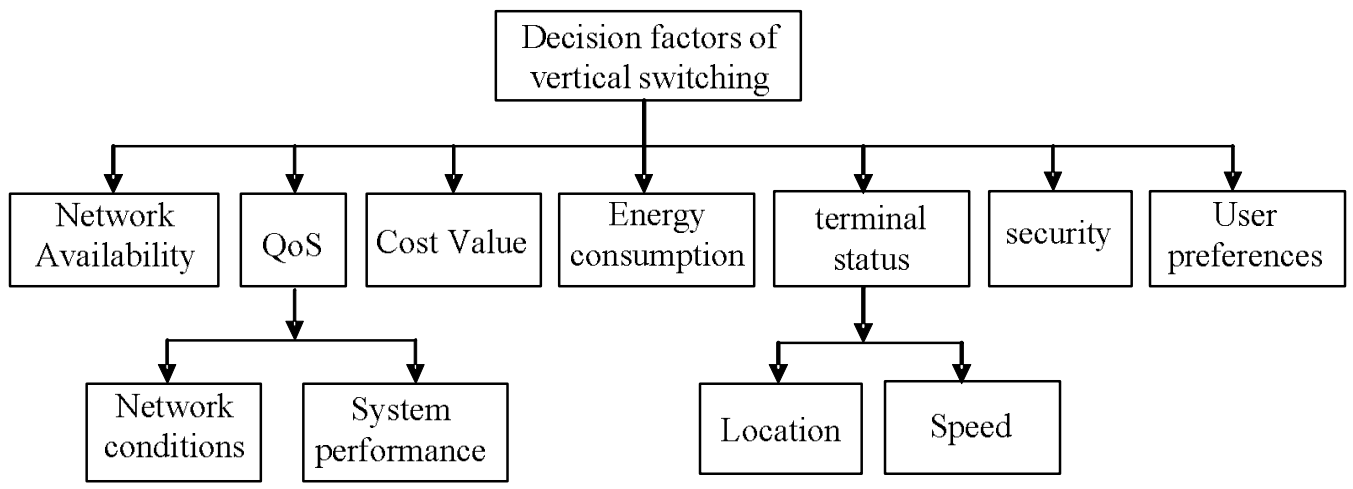

Fig 3. Decision factors for vertical switching

\section{Channel protection of Heterogeneous Network}

The basic channel protection method in heterogeneous network is achieved by multi-path routing technology, which provide more than one paths for the data transmitting and receiving. Additional, Some protocols are introduced to manage packet transmission rule, to ensure establishing a reliable route between source and destination node. Although multi-path routing software occupied large memory and CPU resources, compared with the single-path routing, it improves the utilization of the network, enhances performance, and extends the network life cycle.

For power distribution communication network, nodes in certain regions are intensive and data traffic is relatively large. Real-time transmission is not important but high reliability is required, such as meter reading and other data collection services[7]. If using single-path routing, traffic congestion will be caused and energy consumption of some for warding nodes is excessive, network collapse may occur. Therefore, establishment of multi-path routing for those situation is necessary.

In this project, a weight based multi-path routing algorithm for the intelligent distribution electricity environment was proposed. According to different node's routing mechanism, we set up several number of independent route to the destination node, and choose two paths of the smallest weight as the primary path and backup path, respectively. When the primary path disconnected, the source node automatically switched to backup one. If the backup path failed, a weak ring topology with the relay node will be established. So reliable transmission of data could be guaranteed. The algorithm is shown in Fig. 4.

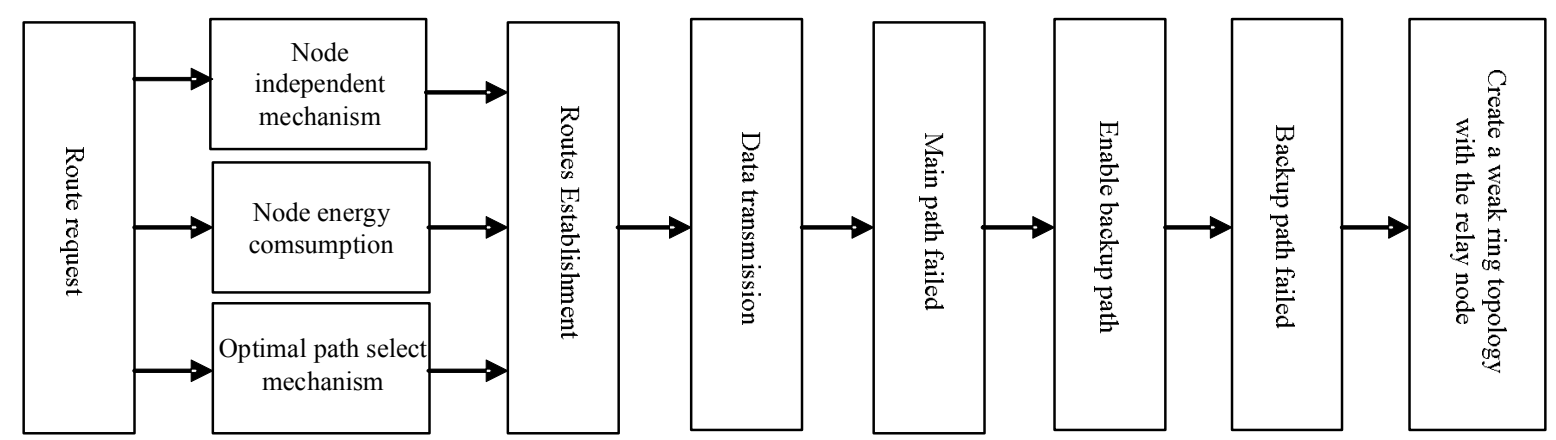

Fig 4. The block diagram of the multi-path routing algorithm 


\section{Conclusion}

Diversification of power distribution automation service makes requirements of data transmission performance increasing rapidly[8], single access technology can not fully meet the demands of users in all applications. To overcome the disadvantages for traditional network and ensure the security of distribution grid, new access technologies such as microwave, 4G wireless also deployed experimentally. In a multi-access network environment, issues caused by heterogeneous network architecture should be considered. In order to improve performance and reduce operation and maintenance cost, the future work will focus on maximum utilization of resources, effective use of the network path and more reliability of communication.

\section{Acknowledgment}

This work was financially supported by the 2015 project of State Grid Corporation of China: Research of key technology of multi-service access network for smart grid communication.

\section{References}

[1] Xiang-zhen LI, Qing-su HE, Ji-sheng SUN: Research and application on communication technology in smart distribution and utilization grid, Electric Power. 44 (2014), pp 78-81.(In Chinese) [2] Chang-guo ZHAI, Yong-biao YANG: Study on Communication Technique for Power Distribution and Consumption Concept of Smart Grid, Applied Mechanics and Materials, 278 (2013), pp 1956-1961.

[3] Xiao-hong LIANG: Communication project design of electric power distribution network based on EPON. Optical Communication Technology. 37 (2013), pp 38-41.

[4] Peng-bo SI, Qian ZHANG, F. Richard and Yan-hua ZHANG: QoS-Aware Dynamic Resource Management in Heterogeneous Mobile Cloud Computing Networks. China Communications, 5 (2014), pp 144-159.

[5] Yass K.Salih, Ong Hang See, Rabha W.Ibrahim, Salman Yussof and Azlan Iqbal: An overview of intelligent selection and prediction method in heterogeneous wireless networks, Journal of Central South University, 21 (2014), pp 3138-3154.

[6] Jian JIANG, Jian-dong LI, Xin-yi LIU: Network selection policy based on auction theory in heterogeneous wireless communication systems, SCIENCE CHINA, 4 (2015),pp 93-102.

[7] Wen-peng LUAN, Guan WANG, Da-qing XU. Advanced Metering Infrastructure Solution Supporting Multiple Services and Business Integration, Proceedings of the CSEE, 29 (2014). Pp 5088-5095.

[8] Yi Xin YU, Yuan ZENG, Hong LIU and Bing LIU: Challenges and R\&D opportunities of smart distribution grids in China, SCIENCE CHINA, 8 (2014), pp1588-1593. 